\title{
Analysis of the changing Solar Radiation Angle on Hainan Island
}

\author{
${\text { Zhiwu } \mathrm{Ge}^{1} \text {, JingJingHuang }}^{2}$, HongxiaLi ${ }^{2}$ and HuizhenWang ${ }^{2}$ \\ ${ }^{1}$ Hainan normal University, Physics Department, No. 99, Long Kun south road, Haikou, China \\ ${ }^{2}$ Hainan normal University, Electronic Information and Technology Department, No. 99, Long Kun south road, Haikou, China
}

\begin{abstract}
As the only tropical provinces in China, Hainan province has advantageous geographical location, and abundant solar energy resources. But because of Local ideas and habits, especially the lack of theoretical research on local solar resources, development and application of solar energy in Hainan is almost blank. In this paper, we studied the variation regularity of sunlight angle on Hainan tropical island, analyzed the revolution and rotation of the earth, and the change rule of sunlight angle caused by the sun's movement between the tropic of cancer and the tropic of capricorn, deduced the change rule of sunlight angle in the spring equinox, the autumnal equinox, summer solstice and winter solstice day, and got the movement rules of solar elevation angle throughout the year. Theoretic analysis is consistent with field measurement results. These rules are of importance and can effectively guide the local People's daily life and production, such as the reasonable layout of the buildings, floor distance between different heights of buildings, the direction of the lighting windows of tall buildings, installation angle of photovoltaic panels, and other similar solar energy absorbing and conversion equipment.
\end{abstract}

\section{Preface}

With the growing development of science and technology, people's living standard is increasing day by day, the material demand is growing also. The resource consumption will greatly increase. But as the earth's nonrenewable resources is becoming less and less, it is possible to exhaust the non-renewable resources in the near feature. In the exploration process of new energy, it is found that the light energy from the sun is almost inexhaustible, and it is the first choice to take the place of the non-renewable resources $[1,2,3]$.

In recent years, under national policy support, solar energy has become a fast growth energy application form all over the world. Our country also spare no effort in the development and applications of solar energy $[1,2,3]$.

In order to understand and use the solar energy fully, it is necessary to research and grasp the change rules of the solar radiation angle, and to improve the efficiency of the use of solar energy.

Due to the different latitude, the sunlight angle are also different in the same time, and this paper study the changing rules of the solar inclination angle in Hainan tropical island.

\section{The relevant laws of the movement of sunlight angle}

Every day, in the morning, sunlight angle of the sun is the smallest, with the rotation of the earth, solar altitude angle changes from the original small to large, At noon to reach the maximum, which is the maximum altitude angle of the Sun. Subsequently, the solar altitude angle is gradually reduced from noon to dusk. At dusk reach the minimum as shown in Figure 1.

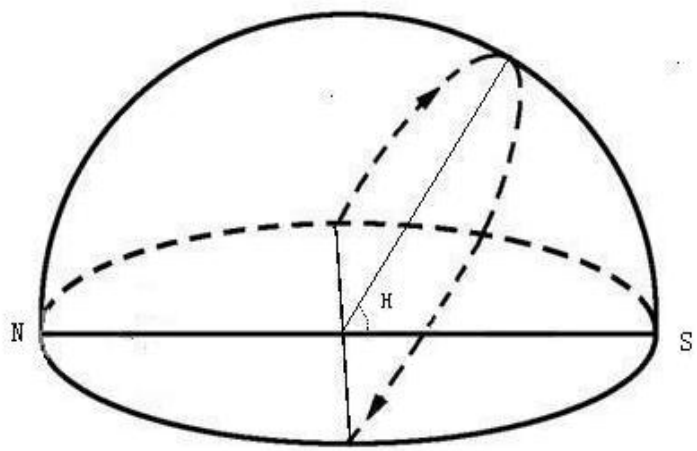

Figure 1. The trajectory of the sun.

The direct point of the sun is at 12 o'clock at noon in the local and moves along the trajectory as shown in Figure 2 [4].

The vernal equinox day just before and after March 21 st, the direct point of sun near the equator $\left(0^{\circ}\right)$, to move from north to the tropic of cancer $\left(23^{\circ} 26^{\prime} \mathrm{N}\right)$, this time is summer solstice before and after June $22 \mathrm{nd}$. Then from the North to the South, moving to near the equator $\left(0^{\circ}\right)$.This time is autumnal Equinox before and after September 23rd. Finally moved to near Capricorn $\left(23^{\circ}\right.$ 26 'S), before and after the December 22nd. Since then, 
continued move circularly from South to North. The movement of the direct point of the sun brings the change of the year round, while the length of day and night changes, such as from long to short or from short to long.

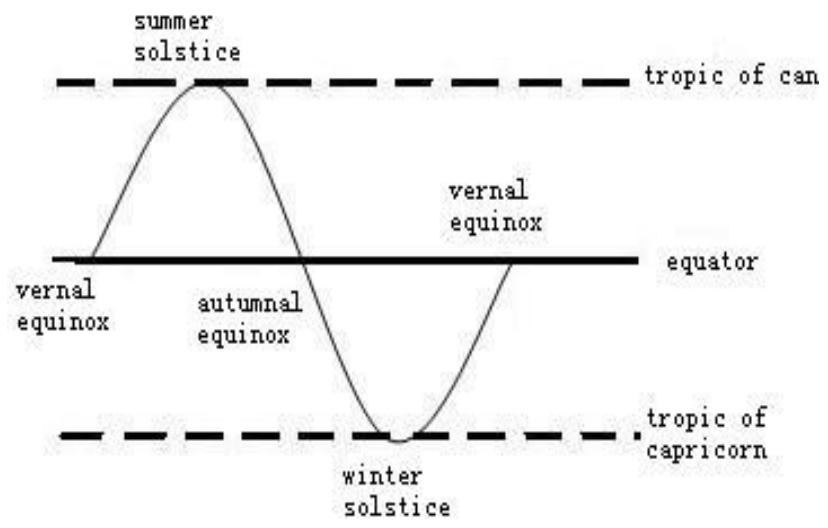

Figure 2. The trajectory of the direct point of the sun.

When the solar altitude angle is equal to 0 degrees in the terminator line, Half of the solar altitude angle of the earth Day is more than 0 degrees, Half of the solar altitude angle of the earth night is less than 0 degrees, can't see the Sun. When the parallel. When direct point of the sun located is 90 degrees, reaching half of the maximum solar altitude angle of the day earth. The solar altitude angle is decreasing along the north and south, with the change of latitude, in the same hemisphere, the latitude changes 1 degree, the angle reduced by 1 degree, just like different hemisphere. Therefore, we can know the latitude of the sunlit point of the sun at a certain time, then it can be inferred that the solar altitude angle at the same time in any place. Thus we can deduce the formula (1) [4].

$$
H=90^{\circ}-|\theta-\delta|
$$

$\mathrm{H}$ is the sunlight angle, the latitude which direct point of the sun located, the local latitude we desired. 90 degrees subtract the latitude difference then reserve the absolute value, that is the desired local solar altitude angle. What needs to pay attention is that if the direct point of the sun and the desire place in the same hemisphere of the earth, to do subtraction between the two places to get the latitude difference then reserve the absolute value. If the direct point and the desire place in the different hemisphere of the earth, figure out the sum of the two places. For example, when the direct point of the sun at 40 degrees north latitude, figure out the solar altitude angle at 60 degrees north latitude. Apply the formula 2-1, 10 degrees north latitude, for the local latitude is $20^{\circ}$ north latitude, the difference between the two is $-20^{\circ}$. Due to The absolute value is 20 degrees in the northern hemisphere Then the solar altitude angle at 60 degrees north latitude is $\mathrm{H}=90^{\circ}-70^{\circ}=20^{\circ}$. If this time, the direct point of the solar altitude angle at 10 degrees south latitude, asking for figuring out the solar altitude angle at $50^{\circ}$ north latitude. Also apply the formula 2-1, 10 degrees south latitude, for the local latitude is $50^{\circ}$ north latitude. Because the two places in the different hemispheres of earth, adding together: $10^{\circ}+60^{\circ}=70^{\circ}$.
Then the solar altitude angle at 60 degrees north latitude is $\mathrm{H}=90^{\circ}-70^{\circ}=20^{\circ}$, of course, even don't know the latitude of direct point of the sun at this time , we still able to calculate the latitude that the sun located by the date, then figure out the solar altitude angle of the place, then deduced the solar altitude angle at the place, as shown in formula (2) [4].

$$
\begin{aligned}
& E D=0.3723+23.2567 \sin \theta+0.1149 \sin 2 \theta- \\
& -0.1712 \sin 3 \theta-0.758 \cos \theta+0.3656 \cos 2 \theta \\
& +0.0201 \cos 3 \theta
\end{aligned}
$$

In formula(2), ED is the solar declination angle that we required, expressed in degrees. The day angle is $\theta$, $\theta=2 \pi t / 365.2422$, the angle of $\pi$ is 180 degrees. The time that the earth makes one revolution is 365.2422 days. The calculation formula of it is shown as in formula (3).

$$
t=N-N_{0}
$$

Annual accumulation day refers to the total number of days in a year. For example, January 1st's annual accumulation day is 1, December 30st's annual accumulation day is 364 . Of course, December $31 \mathrm{st}^{\text {'s }} \mathrm{s}$ annual accumulation day is 365 in a common year, December 31st's annual accumulation day is 366 if it is a leap year, and so on. Derivation of formulas is shown as in formula (4)[4].

$$
N_{0}=79.6764+0.2422 *(X-1985)-\operatorname{int}[(X-1985) / 4]
$$

Among them, $\mathrm{X}$ in the formula (4) is the year of that time, then put formula (4) into the formula(3) obtained formula (5).

$$
t=N-79.6764-0.2422 *(X-1985)+\operatorname{int}[(X-1985) / 4]
$$

\section{Analysis of the movement laws of sunlight angle in Hainan province}

Hainan Province is located at the southernmost of China. The Qiongzhou Strait is to its north delimiting Hainan and Guangzhou. It faces Democratic Republic of Vietnam across the Beibu Gulf in the west, Taiwan province across the South China Sea in the east. In the southeast and south, it is adjacent with Malaysia, Brunei and Philippines in the South China Sea. It's the China's largest province including Hainan island, Xisan island, Zhongsha island, Nansha island and its sea. The province's total land area is 35.4 thousand square kilometres and its sea area is 2 million square kilometres. Hainan island is between latitude $18^{\circ} 10^{\prime} \sim 20^{\circ} 10^{\prime}$ to north and longitude $108^{\circ} 37^{\prime} \sim 111^{\circ} 03^{\prime}$ to east. Its outline is like to a oval and big pear. Its major axis is 290 kilometres long across northeast to southwest and is 180 kilometres wide across northwest to southeast. Hainan island's area is 33.9 thousand square kilometres. 
Hainan is the second largest island that is only smaller than Taiwan island.

Next, detail analysis of changing solar radiation angle on Hainan island will be given in the vernal and autumnal equinoxes, the summer solstice and winter solstice.

\subsection{Winter Solstice}

December 22nd is winter solstice. When the solar elevation angle locates at tropic of capricorn $\left(23^{\circ} 26^{\prime}\right.$ S ) (see Figure.2).In the winter solstice of north hemisphere, the sun irradiates directly and the antarctic circle appears polar day. The sun of equator's area rises from due east by south $23^{\circ} 26^{\prime}$ vertically. It goes down from due west by south $23^{\circ} 26^{\prime}$ vertically. The north hemisphere is in winter solstice. However, south hemisphere is in summer solstice. The daytime of north hemisphere is the shortest throughout the year. The length of objects' shadow reaches the longest. The noon's solar elevation angle is smallest. At this moment of south hemisphere, the daytime reaches the longest, the shadows of objects become the shortest and noon's solar elevation angle is the biggest. Hainan island's daytime is shortest that is about 11 hours, and night time is the longest. The solar elevation angle of noon is the smallest and the shadows of objects is longest. The sun irradiates the tropic of capricorn directly and the solar elevation angle is 90 degree. We can get the solar elevation angle of Hainan at noon by using formula 2-1.The angle of subsolar point is $23^{\circ} 26^{\prime} \mathrm{S}$. The geographical location of Hainan is latitude $18^{\circ} 10^{\prime} \mathrm{N}$ to $20^{\circ} 10^{\prime} \mathrm{N}$ that is and it is between $18^{\circ} 10^{\prime}$ and $20^{\circ} 10^{\prime}$. Using formula $2-1$, because of the subsolar point is located at south hemisphere. But Hainan is at $18^{\circ} 10^{\prime} \mathrm{N}$ to $20^{\circ} 10^{\prime} \mathrm{N}$ which is in north hemisphere. Due to locating at different hemispheres, we plus two latitudes that is $41^{\circ} 36^{\prime} \mathrm{N}$ to $43^{\circ} 36^{\prime} \mathrm{N}$. So $\mathrm{H}=90^{\circ}-\left(\begin{array}{ll}41^{\circ} 36^{\prime} \sim 43^{\circ} 36^{\prime}\end{array}\right)=$ ( $48^{\circ} 24^{\prime} \sim 46^{\circ} 24^{\prime}$ ). Midday solar elevation angle is about $48^{\circ} 24^{\prime}$ to $46^{\circ} 24^{\prime}$ on December $21 \mathrm{st}$.

\subsection{Spring Equinox}

The sun moves from the tropic of capricorn $\left(23^{\circ} 26^{\prime}\right.$

$\mathrm{S}$ ) to north. On March 21st which is spring equinox, subsolar point locates at equator. Different regions have the same way that the positions of sunrise and sunset are due east, due west respectively(everywhere but south pole).And with latitude going up, the dihedral angle between solar irradiation and the horizon changes from $90^{\circ}$ to $0^{\circ}$.

The time of day and night is equal in the south and north hemisphere, but seasons are opposite. The north hemisphere is in spring equinox, relatively, The south hemisphere is in autumn equinox. In north hemisphere, The time of day and night changes to that day is longer than night. With the daytime increasing, the objects' shadow decreases and the midday solar elevation angle becomes bigger. But south hemisphere is complete opposite. Hainan is located at north hemisphere. Using formula 2-1, we can calculate Hainan's midday solar elevation angle. The solar elevation angle of subsolar point is $0^{\circ}$. The geographical location of Hainan is latitude $18^{\circ} 10^{\prime} \sim 20^{\circ} 10^{\prime}$ to north that is $=\left(18^{\circ}\right.$ $\left.10^{\prime} \sim 20^{\circ} 10^{\prime}\right)$. Using formula 2-1, because subsolar point is at equator and Hainan is located at north hemisphere, we get the two latitudes substracted and then get the absolute value that is $\mathrm{H}=90^{\circ}-0-\left(18^{\circ} 10^{\prime} \sim\right.$ $\left.20^{\circ} 10^{\prime}\right)=\left(71^{\circ} 50^{\prime} \sim 69^{\circ} 50^{\prime}\right)$. Hainan's midday solar elevation angle is about $71^{\circ} 50^{\prime}$ to $69^{\circ}$ $50^{\prime}$. At this moment, the time of day and night changes to that the time of day is equal to night. With the time going by, daytime is shorter and the object's shadow of night are shorter, too.

\subsection{Summer Solstice}

The sun moves northwards from equator $\left(0^{\circ}\right)$ to the tropic of cancer $\left(23^{\circ} 26^{\prime} \mathrm{N}\right)$. On June 22nd, subsolar point is at the tropic of cancer. On north hemisphere's summer solstice, the sun irradiates the tropic of cancer directly. Within the Antarctic circle, there appears the polar night. In equator region, the sun rises from due east by north $23^{\circ} 26^{\prime}$ vertically and it goes down from due west by north vertically. The higher the latitude is, the larger the angle which deviates northeast is. In polar night, the position of sunrise and sunset becomes one point, locating at due north. The daytime of north hemisphere is the longest and the night time of south hemisphere is the longest. The north hemisphere is in summer and the south hemisphere is in winter. The daytime of north hemisphere reaches the longest throughout the year.

In the north of tropic of cancer, midday solar elevation angle is the largest in the year. And objects' shadow is the shortest. At latitude $23^{\circ} 26^{\prime}$ to north, shadow coincides with body. The night time of south hemisphere is the longest. The midday solar elevation angle of south hemisphere is the smallest and the shadow reach the shortest. At this time, the daytime of Hainan is longest. On June 22nd, 2014, the sun rises at 06:09:04.It is highest at 12:49:58 and it goes down at 19:30:15. The daytime of that day reaches 13 hours 21 minutes 11 seconds that is the longest. The change of solar elevation angle experiences two periods. Firstly, it moves northwards from equator to latitude $18^{\circ} 10^{\prime} \sim 20^{\circ}$ $10^{\prime}$ to north. Hainan's solar elevation angle becomes larger and larger. The daytime changes from short to long. The shadow is shorter. Until May 13th to May 22nd, the midday solar elevation angle of Hainan is max that is 90 degrees and the shadow coincides with body. Secondly, the sun moves northwards from $20^{\circ}$ north latitude to the tropic of cancer $\left(23^{\circ} 26^{\prime} \mathrm{N}\right)$. In the process, the midday solar elevation angle of Hainan changes from big to small, the daytime becomes longer unceasingly and the shadow becomes shorter. Finally, when subsolar point is at the tropic of cancer $\left(23^{\circ} 26^{\prime} \mathrm{N}\right)$, daytime reach the longest in Hainan. At the same time, midday solar elevation angle can be calculated by formula $2-1$. We all know that the solar elevation angle of subsolar point 
equals $23^{\circ} 26^{\prime} \mathrm{N}$. The geographical location of Hainan is latitude $18^{\circ} 10^{\prime} \sim 20^{\circ} 10^{\prime}$ to north that is $=\left(18^{\circ}\right.$ $10^{\prime} \sim 20^{\circ} 10^{\prime}$ ) . Using formula $2-1$, because of subsolar point is at the tropic of cancer and Hainan is located at north hemisphere, we get the two latitude substracted and then get the absolute value that is $\mathrm{H}=90^{\circ}-23^{\circ} 26^{\prime}-\left(\begin{array}{llll}18^{\circ} & \left.10^{\prime} \sim 20^{\circ} 10^{\prime}\right)\end{array}=\left(84^{\circ}\right.\right.$ $\left.44^{\prime} \sim 86^{\circ} 44^{\prime}\right)$. Midday solar elevation angle is about $84^{\circ} 44^{\prime}$ to $86^{\circ} 44^{\prime}$ in Hainan. At this moment, daytime is the longest and is going to be shorter. Meanwhile, the night time changes from short to long. The midday solar elevation angle changes from small to big and the shadow changes long to short.

\subsection{Autumn Equinox}

The sun moves from tropic of capricorn $\left(23^{\circ} 26^{\prime} \mathrm{S}\right)$ to south. On September $23^{\text {rd }}$, which is spring equinox, subsolar point locates at equator. The day and night is divided equally .Different regions have the same way that the position of sunrise and sunset are due east, due west respectively(everywhere but south pole). And with latitude going up, the dihedral angle between solar irradiation and the horizon changes from $90^{\circ}$ to $0^{\circ}$. That is to say solar elevation angle changes from $90^{\circ}$ to $0^{\circ}$. The time of day and night is equal in the south and north hemisphere, but seasons are opposite. The north hemisphere is in autumn equinox, relatively, the south hemisphere is in spring equinox. In north hemisphere, the time of day and night changes to that night is longer than day. With the night time increasing, the objects' shadow increases and midday solar elevation angle becomes smaller. But south hemisphere is complete opposite. The change of solar elevation angle experience two periods. Firstly, it moves southwards from the tropic of cancer to $18^{\circ} 10^{\prime}$ to $20^{\circ} 10^{\prime}$ north latitude whose time is from July 23 rd to August 1 st .And the midday solar elevation angle of Hainan is max that is 90 degrees and the shadow coincides with body. With the time going by, the sun moves to south unceasingly, solar elevation angle becomes smaller and smaller in Hainan. The daytime becomes shorter and shorter and the night time increases. The shadow is longer and longer. Secondly, subsolar point is at equator $\left(0^{\circ}\right)$ in autumn equinox. According to formula 2-1, we can calculate the midday solar elevation angle of Hainan. The solar elevation angle of subsolar point is $0^{\circ}$. The geographical location of Hainan is latitude $18^{\circ} 10^{\prime} \sim 20^{\circ} 10^{\prime}$ to north that is = $\left(\begin{array}{ll}18^{\circ} 10^{\prime} \sim 20^{\circ} 10^{\prime}\end{array}\right)$. Using formula 2-1, because of subsolar point is at the equator and Hainan is located at north hemisphere, we get the two latitudes substracted and then get the absolute value that is $\mathrm{H}=90^{\circ}-10^{\circ}$ $\left(18^{\circ} 10^{\prime} \sim 20^{\circ} 10^{\prime}\right)=\left(71^{\circ} 40^{\prime} \sim 69^{\circ}\right.$ $40^{\prime}$ ) .Hainan' $\mathrm{s}$ midday solar elevation angle is about $71^{\circ} 40^{\prime}$ to $69^{\circ} 40^{\prime}$. At this moment, Hainan's daytime is the longest and is going to be equal with night time. With the time going by, the daytime is shorter and the night time is longer. The shadow changes from short to long.

\subsection{Summery}

Subsolar point moves from the tropic capricorn $\left(23^{\circ}\right.$ $\left.26^{\prime} \mathrm{S}\right)$ of winter solstice to the equator $\left(0^{\circ}\right)$ of spring equinox in Hainan, and then moves to the tropic of cancer $\left(23^{\circ} 26^{\prime} \mathrm{N}\right)$, and then moves to the equator $\left(0^{\circ}\right)$ of autumn equinox, finally returns to the tropic of capricorn $\left(23^{\circ} 26^{\prime} \mathrm{S}\right)$. It takes one year for a cycle. It's winter solstice when the sun is at the tropic of capricorn $\left(23^{\circ} 26^{\prime} \mathrm{S}\right)$. Hainan is at $18^{\circ} 10^{\prime}$ to $20^{\circ}$ $10^{\prime}$ north latitude. Its daytime is the shortest. The sun rises from southeast and the shadow is toward northwest. The midday solar elevation angle is $48^{\circ} 24^{\prime}$ to $46^{\circ}$ $24^{\prime}$. The subsolar point moves from the tropic of capricorn $\left(23^{\circ} 26^{\prime} \mathrm{S}\right)$ to equator $\left(0^{\circ}\right)$. The daytime of Hainan is longer,the solar elevation angle is bigger and the shadow is shorter. Firstly, The subsolar point is at equator in spring equinox that is March 21st. Hainan is at $18^{\circ} 10^{\prime}$ to $20^{\circ} 10^{\prime}$ north latitude. The midday solar elevation angle is $71^{\circ} 50^{\prime}$ to $69^{\circ} 50^{\prime}$. The daytime is equal with the night time theoretically. The position of sunrise and sunset are due east, due west respectively. When the subsolar point moves northwards to the tropic of cancer $\left(23^{\circ} 26^{\prime} \mathrm{N}\right)$, the daytime of Hainan is longer and longer. The solar elevation angle of Hainan changes from small to large and it reaches the biggest in March 13th to March 22nd .Secondly, the subsolar point moves to north unceasingly. The daytime of Hainan becomes longer and longer. In June 22nd ,the subsolar point reaches the tropic of cancer $\left(23^{\circ} 26^{\prime}\right.$ $\mathrm{N}$ ). At this moment, the daytime of Hainan is the max. Hainan is at latitude north $18^{\circ} 10^{\prime}$ to $20^{\circ} 10^{\prime}$. The midday solar elevation angle is $84^{\circ} 44^{\prime}$ to $86^{\circ} 44^{\prime}$. The daytime is the longest throughout the year. The sun rises from northeast and goes down from southwest. Thirdly, the subsolar point moves southwards from the tropic of cancer $\left(23^{\circ} 26^{\prime} \mathrm{N}\right)$. And it reaches equator $\left(0^{\circ}\right)$ in September 23rd .Meanwhile, the midday solar elevation angle in Hainan changes from small to big. And then it is the max in July 23rd to August 1st.With the subsolar point moving southwards, the solar elevation angle changes from big to small. In September 23rd the solar elevation angle is $71^{\circ} 50^{\prime}$ to $69^{\circ} 50^{\prime}$. The daytime is shorter and the shadow is longer. Finally, the subsolar point moves from equator $\left(0^{\circ}\right)$ and reach the tropic of capricorn $\left(23^{\circ} 26^{\prime} \mathrm{S}\right)$ in December 22nd.The midday solar elevation angle changes from big to small, the daytime becomes shorter and shorter and the shadow changes from short to long.

The movement rules of solar elevation angle throughout the year in Hainan is shown in figure 3 .

In winter solstice that is December 22nd, the midday solar elevation angle is $\min \left(48^{\circ} 24^{\prime} \sim 46^{\circ} 24^{\prime}\right)$ throughout the year. In spring equinox that is March 21st, it rises at $71^{\circ} 50^{\prime}$ to $69^{\circ} 50^{\prime}$ and reaches the max $\left(90^{\circ}\right)$ in May 13th. In June 22nd that is summer solstice, it goes down at $84^{\circ} 44^{\prime}$ to $86^{\circ} 44^{\prime}$. With the subsolar moving southwards, the solar elevation angle of Hainan reaches the max again around July 23rd. Thus it 
can be seen that there are two times which the midday solar elevation angle of Hainan reaches the max. And then, with the subsolar point moving southwards, the midday solar elevation angle of Hainan decreases at $71^{\circ}$ $50{ }^{\prime}$ to $69^{\circ} 50^{\prime}$ in September 23rd .In December 22nd, the subsolar point returns to the tropic of capricorn $23^{\circ} 26^{\prime} \mathrm{S}$ ) and the solar elevation angle of Hainan is the $\min \left(48^{\circ} 24^{\prime} \sim 46^{\circ} 24^{\prime}\right)$. By analysing the change of the midday solar elevation angle throughout the year, then we look how the midday solar elevation angle changes in a month.

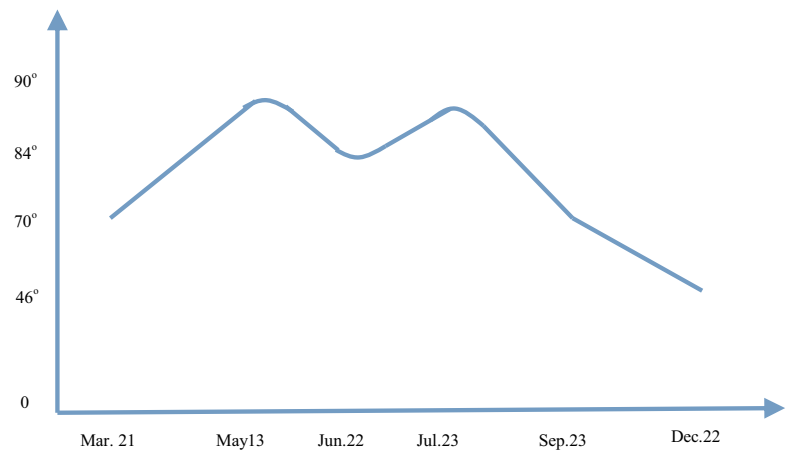

Figure 3. Hainan's solar elevation angle throughout the year.

For example, In November 1st, the change of subsolar point has its specific track in the year. Using formula 22, we can calculate that the subsolar point of that day is at $14^{\circ} 14^{\prime} \mathrm{S}$. That day, the subsolar point is at south hemisphere. According to formula 2-1,we can calculate that the midday solar elevation angle of Hainan $\left(18^{\circ}\right.$ $10^{\prime} \sim 20^{\circ} 10^{\prime}$ ) is about $57^{\circ} 36^{\prime}$ to $56^{\circ} 36^{\prime}$.On this account, we can calculate midday solar elevation angle of Hainan everyday. The result is shown in table 1.

Table 1. Hainan midday sun angle in November.

\begin{tabular}{|l|l|l|l|l|l|}
\hline Date & Angle & Date & Angle & Date & Angle \\
\hline 1 & $57^{\circ} 36^{\prime}$ & 11 & $54^{\circ} 35^{\prime}$ & 21 & $52^{\circ} 03^{\prime}$ \\
\hline 2 & $57^{\circ} 16^{\prime}$ & 12 & $54^{\circ} 18^{\prime}$ & 22 & $51^{\circ} 50^{\prime}$ \\
\hline 3 & $56^{\circ} 57^{\prime}$ & 13 & $54^{\circ} 02^{\prime}$ & 23 & $51^{\circ} 37^{\prime}$ \\
\hline 4 & $56^{\circ} 39^{\prime}$ & 14 & $53^{\circ} 46^{\prime}$ & 24 & $51^{\circ} 24^{\prime}$ \\
\hline 5 & $56^{\circ} 20^{\prime}$ & 15 & $53^{\circ} 03^{\prime}$ & 25 & $51^{\circ} 12^{\prime}$ \\
\hline 6 & $56^{\circ} 02^{\prime}$ & 16 & $53^{\circ} 15^{\prime}$ & 26 & $51^{\circ}$ \\
\hline 7 & $55^{\circ} 44^{\prime}$ & 17 & $53^{\circ}$ & 27 & $50^{\circ} 49^{\prime}$ \\
\hline 8 & $55^{\circ} 26^{\prime}$ & 18 & $52^{\circ} 45^{\prime}$ & 28 & $50^{\circ} 38^{\prime}$ \\
\hline 9 & $55^{\circ} 09^{\prime}$ & 19 & $52^{\circ} 31^{\prime}$ & 29 & $50^{\circ} 27^{\prime}$ \\
\hline 10 & $54^{\circ} 52^{\prime}$ & 20 & $52^{\circ} 17^{\prime}$ & 30 & $50^{\circ} 17^{\prime}$ \\
\hline
\end{tabular}

As shown in table1, Hainan' sun Angle decreases in November, the day time get shorter and shorter.

\section{Conclusion}

The special movement laws of sunlight angle in Hainan province has been analyzed, the results showed the different characteristic of solar energy resources in Hainan compared with that in inland. According to the above analysis, solar elevation angle throughout the year changes along unique bimodal curve on Hainan island. It's easy to verify the results, set a known length of a stick at noon, measure the length of its shadow, and the sun angle can be calculated out. Above analysis results are also in accordance with the curve got according to the local meteorological data [5].

The results can guide daily life and production of local residents effectively, and provide direction for economically and reasonably using solar energy. For example, options of building orientation, orientation of heat acquisition plate or photovoltaic panels, etc., are all closely related with the angle of the sun.

\section{Acknowledgement}

Thanks for the funding of Hainan province natural science foundation (Grant Number 20165198).

\section{References}

1. http://xueshu.baidu.com/s?wd=paperuri:(c8a0b8d51f $472 \mathrm{cede} 3 \mathrm{~d} 00 \mathrm{a} 617 \mathrm{f} 9 \mathrm{c} 147 \mathrm{c}) \&$ filter $=$ sc_long_sign\&sc ks_para $=\mathrm{q} \% 3 \mathrm{D} \% \mathrm{E} 6 \% \mathrm{~B} 5 \% \mathrm{~B} 7 \% \mathrm{E} 5 \% 8 \mathrm{D} \% 97 \% \mathrm{E} 7 \%$ 9C\%81\%E5\%A4\%AA\%E9\%98\%B3\%E8\%83\%BD $\%$ E5\%88\%A9\%Е7\%94\%A8\%Е7\%8A\%B6\%Е5\%86 $\%$ B5\%E8\%B0\%83\%E6\%9F\%A5\&tn=SE_baiduxue shu_clgjeupa\&ie $=$ utf8\&sc_us $=7327178283693853975$

2. Xufei. zhang. Renpeng. Xiao, Science and Technology and Equipment, 12, 35-37, (2010).

3. Yi .shen, Thesis of Lanzhou University, 1-13,(2014)

4. Hanyun. Huang, Principle of solar photovoltaic power generation applications, 9-15, (2012)

5. Changan. wang. Guojie. wang, Journal of Hainan Normal University(Natural Science), 168-173, (2011) 